\title{
Analysis of the stability of phycocyanin when trehalose and citric acid are used as protectants in nutraceutical gelatin candies under in vitro digestion assays'
}

\author{
Josmar Araud VÁZQUEZ-RODRÍGUEZ¹, Froylán Mario Espinoza ESCALANTE ${ }^{1 \star}$
}

\begin{abstract}
Natural pigments are high value molecules for food industry as well as pharmacy, perceived as the best choice for today's consumers given their origin and safety. However, its use is limited by its lability which hinders its application in products. In this work there was evaluated the stability of phycocyanin $\mathrm{C}$ in gelatin candies when added with trehalose and citric acid; the formulated candies were digested in synthetic gastric juice with pepsin. There were calculated predictive equations correlating the concentration of pigment as function of time, additives, and enzymatic presence. It was observed that phycocyanin can supports the gastric juice and pepsin when combined with trehalose for enough time to pass thru the digestive tract. It was concluded that the inclusion of trehalose in the formulation led to a longer stability of the pigment. Besides, it was determined that gelatin candies are a good vector to deliver phycocyanin $\mathrm{C}$ to the intestine.
\end{abstract}

Keywords: arthrospira; microalgae; dietary supplement; antioxidant.

Practical Application: Gelatin candies are a suitable way to deliver phycocyanin C into the intestine.

\section{Introduction}

The term nutraceutical comes from "nutrition" and "pharmaceutical", then refers to food and ingredients with health benefits (Escalante \& Pérez-Rico, 2021). Microalgae are a good source of these kind of molecules including phycobiliproteins, sterols, pigments, enzymes, carbohydrates, fatty acids and toxins, which have a wide range of applications in the cosmetic, pharmaceutical and food industries (Odjadjare et al., 2017). Given their designation as generally regarded as safe, these microorganisms can be administrated without special preparation (Khan et al., 2018). Among the variety of microalgae and cyanobacteria recently exploited for industrial purposes, Arthrospira spp. is a referent. It can be grown to produce proteins, essential fatty acids and phycobiliproteins (Milledge, 2011).

The global market of nutraceutical was valued in 79.5 billion dollars in 2017 and is expected to grow up to 141.7 billion dollars in 2025; this represents an interesting niche for new products (Izquierdo \& Feldman, 2019). Only phycobiliproteins had a market value of 18.5 million dollars in 2018 and it is projected to increase over 30 million in 2025 with an annual growth rate of $8.6 \%$ given its use as additive in beverages and cosmetics (Ahuja \& Mamtani, 2019).

The phycobiliproteins gained importance mainly in food and nutraceuticals industries because these lasts are looking for natural and active colorants; among them, the rarest are blue and violet, thus it has been a wide research for natural colorants to cover this need. Most novel natural blues are gardenia, indigo and phycobiliproteins (Jespersen et al., 2005). Therefore, the main reason to investigate the stability of phycobiliproteins, mainly phycocyanin C (C-PC), under different physicochemical conditions comes from the fact it covers two desirable properties for industry: is chromatic and nutraceutical properties. Depending on its purity ratio, phycocyanin $\mathrm{C}$ can be use as food additive (0.7) or pharmaceutical (4.0) (Kannaujiya et al., 2018; Kefayat et al., 2019). However, its stability is still a challenge, looking for more stable conditions; researchers have tested a variety of factors including temperature, $\mathrm{pH}$, light, and additives (Pérez-Rico et al., 2020).

In this study we have explored the stability of phycocyanin into gelatin candies. Gelatin is the most used hydrocolloid in food and pharmaceuticals; different from other pharmaceutical forms, gummies are highly accepted given its texture and easy deglutition, specially for pediatric and geriatric patients (Madrigal et al., 2020). Besides, the use of hydrocolloids inhibits or delays the recrystallization process of sucrose, stabilize emulsions and foams, and contribute to the suspension of solids or acts as bonding agents among several ingredients (Céspedes, 2019). Since their production requires high temperatures, we have included trehalose and citric acid to preserve the pigment from degradation.

Even when most studies have studied the thermal and physicochemical stability of C-PC in the product and under storage conditions, to the best of our knowledge there are no studies related to the use of trehalose as stabilizer of this pigment or the effect of gastric fluids in the integrity of the molecule. 
When thinking in the addition of C-PC as food supplement or nutraceutical, it is important to evaluate the stability of the active in the digestive tract. The main objective of this study was to determine the stability of total phycocyanin (TPC) and $\mathrm{C}$-phycocyanin (C-PC) in gastric fluid, thus we ran an experiment using several formulations which were digested in synthetic gastric fluid with and without peptic enzyme.

\section{Materials and methods}

\subsection{Raw materials}

All chemicals used in this study were purchased in Merck Mexico. Lyophilized phycocyanin powder from Arthrospira platensis, was obtained from Sabia Madre Tierra S.A. de C.V.; food grade trehalose, was provided by Hayasibara Co., LTD.; citric acid, was obtained from Jungbunzlauer de México; the gelatin candy base, was provided by Gomitas Selectas Domi de Jalisco; pepsin, was provided by Dr. Rosa María Camacho Ruiz from CIATEJ.

\subsection{Gelatin candy formulation}

All samples to be analyzed were prepared using a gelatin candy base added with $1 \% \mathrm{~m} / \mathrm{m}$ of phycocyanin powder, which had a purity of 1.04 (food grade phycocyanin), $25.5 \% \mathrm{~m} / \mathrm{m}$ TPC and $14.0 \%$ CPC. This mixture might include $0.05 \% \mathrm{~m} / \mathrm{m}$ trehalose and $0.001 \% \mathrm{~m} / \mathrm{m}$ citric acid. All candies were prepared in the factory Gomitas Selectas Domi de Jalisco according to a multilevel factorial design experimental matrix using a mixing temperature of $48^{\circ} \mathrm{C}\left( \pm 0.5^{\circ} \mathrm{C}\right)$.

\subsection{Simulated gastric juice}

It was prepared according to the FEUM (Mexico, 2018). Briefly, there were dissolved $2.00 \mathrm{~g} \mathrm{NaCl}$ in distilled water and mixed with $7.0 \mathrm{~mL}$ concentrated $\mathrm{HCl}$, this solution was made up to $1 \mathrm{~L}$ with distilled water. The final solution had a $\mathrm{pH}$ of 1.2. To eliminate dissolved gases the solution was heated up to $40{ }^{\circ} \mathrm{C}$ then filtered thru a $0.45 \mu \mathrm{m}$ PVDF membrane with vacuum and holding-up heating, stirring and vacuum for $14 \mathrm{~min}$. Finally, the solution was placed in the dissolution glasses. The digestion temperature was set to $37.1{ }^{\circ} \mathrm{C}\left( \pm 0.5^{\circ} \mathrm{C}\right)$. For all tests, jelly candies were smashed using a mortar and pestle, then samples of $21 \mathrm{~g}$ were placed into the vessels. To evaluate the effect of the gastric enzymes, the previous solution was added with 1824 units of pepsin from porcine gastric mucosa. In both set of tests $5 \mathrm{~mL}$ samples were taken every 30 minutes for a total of 5 samples over 150 minutes. Samples were filtered through a $0.45 \mu \mathrm{m}$ cellulose membrane; the first $2 \mathrm{~mL}$ were discarded, and the remaining solution was read in the spectrophotometer at the corresponding wavelengths.

\subsection{Phycobiliproteins concentration}

Absorbance spectra of C-PC and APC were measured using UV-VIS Spectrophotometer Model 1800 (Shimadzu, Japan). All these absorbance values were measured against a blank of distilled water. All these absorbance values were measured against a blank of distilled water. The amount of each pigment present in the phycocyanin powder, and samples before and after digestion procedures were calculated using the following Equations 1, 2 and 3 (Liu et al., 2012; Wu et al., 2016):

$\mathbf{C}-\mathbf{P C}\left(\mathbf{m g ~ m L}^{-1}\right)=\frac{A_{620}-0.474\left(A_{652}\right)}{5.34}$

$\mathbf{A P C}\left(\mathbf{m g ~ m L}^{-1}\right)=\frac{A_{652}-0.208\left(A_{620}\right)}{5.09}$

$\operatorname{TPC}\left(\mathrm{mg} \mathrm{mL}^{-1}\right)=A P C+C P C$

\subsection{Experimental design and statistical analysis}

There were carried out two experimental designs. The first one was a multilevel factorial design. There were analyzed the effects of the initial size of the product ( 1 and $3 \mathrm{~g}$ ), trehalose concentration $(0$ and $50 \% \mathrm{~m} / \mathrm{m}$ related to phycocyanin powder amount in the product), the amount of citric acid added to the product ( 0 and $0.001 \% \mathrm{~m} / \mathrm{m}$ ) and time of digestion (0 to 150 in intervals of $30 \mathrm{~min}$ each). In the second set of experiments, product size was discarded, the focus was presence or absence of the pepsin and was evaluated along with the other previously described factors.

Multifactor variance analysis (ANOVA), linear regression models and response surface plots for each variable were computed using a statistical software program (Statgraphics 18). The best model for each response variable was obtained by the forward stepwise regression procedure (Neter et al., 1996). Then the optimum pretreatment condition for each variable was obtained using that model.

\section{Results and discussion}

\subsection{Effect of the studied factors in phycocyanin release from gelatin candies using gastric fluid without enzyme.}

Among all the studied factors and their interactions, it was observed that every factor, except for citric acid, was statistically significant with confidence of $95 \%(p<0.05)$. However, the interaction of this acid with other factors such as trehalose were highly significant, nonetheless the presence of trehalose in the formulation had the major positive impact on the preservation of total phycocyanin, Table 1 .

The regression analysis leads us to obtain the following Equation 4 describing the amount of recovered pigment in the gastric juice as a function of all the analyzed factors:

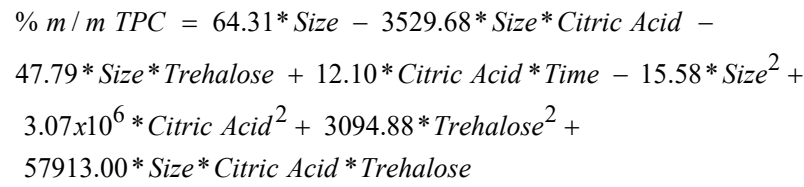

The determination coefficient $\left(\mathrm{R}^{2}\right)$ of 99.96 and $\mathrm{p}$-value of 0.0000 and a standard error of 1.15 suggest a good fitting of Equation 4 to describe the amount of pigment to be released in 
the gastric juice at $95 \%$ of confidence. The maximum amount of total phycocyanin (TPC) recovered was around $58 \% \mathrm{~m} / \mathrm{m}$ of that added initially, Figure 1a. It is important to notice that this result was achieved after 150 minutes of digestion in the product presentation of $1 \mathrm{~g}$ added with trehalose and citric acid. As seen in Figure 1a, there is not a real optimum, but it is suitable for exploratory purposes.

Also, it was analyzed the effect of all four factors in the release of C-PC from the gelatin candies; this time the size showed no significant effect at significance level of $95 \%$, Table 2.

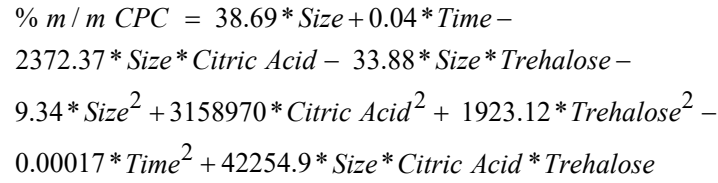

The determination coefficient $\left(\mathrm{R}^{2}\right)$ of 99.94, a p-value of 0.0000 and standard error of 0.86 suggest a good fitting of Equation 5 to describe the $\% \mathrm{~m} / \mathrm{m}$ of C-PC released in the gastric juice as a function of the significant factors and their interactions at $95 \%$

Table 1. Analysis of Variance for \% TPC when using gastric juice without enzyme.

\begin{tabular}{lccccc}
\hline \multicolumn{1}{c}{ Source } & Sum of Squares & Df & Mean Square & F-Ratio & P-Value \\
\hline A:Size & 5.66835 & 1 & 5.66835 & 5.03 & 0.0281 \\
B:Citric Acid & 0.00309 & 1 & 0.00309 & 0.00 & 0.9583 \\
C:Trehalose & 269.094 & 1 & 269.094 & 18.95 & 0.0000 \\
D:Time & 21.3435 & 1 & 21.3435 & 76.98 & 0.0000 \\
AB & 86.6827 & 1 & 86.6827 & 15.76 & 0.0000 \\
AC & 17.7416 & 1 & 17.7416 & 157.63 & 0.0002 \\
BC & 177.502 & 1 & 177.502 & 29.14 & 0.0000 \\
DD & 9.44312 & 1 & 9.44312 & 5.97 & 0.0051 \\
ABC & 32.8144 & 1 & 32.8144 & 6.72768 & 0.0171 \\
CDD & 6.72768 & 1 & 1.12605 & & \\
Total error & 77.6972 & 69 & & & \\
Total (corr.) & 111.46 & 79 & &
\end{tabular}

a)

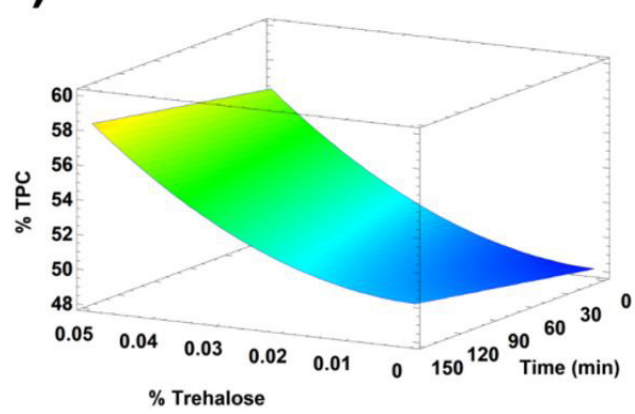

c)

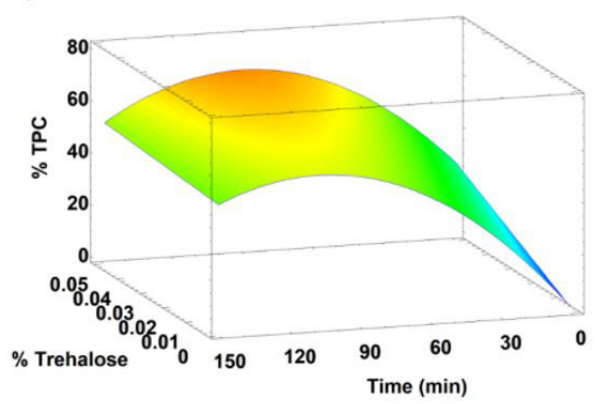

b)
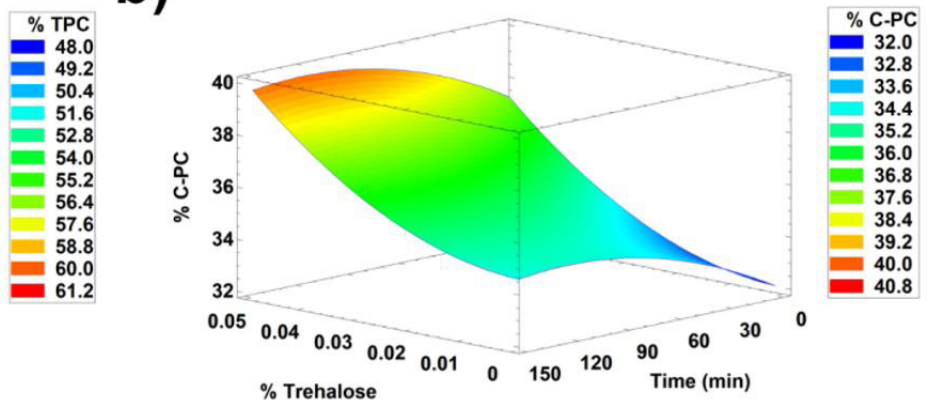

d)

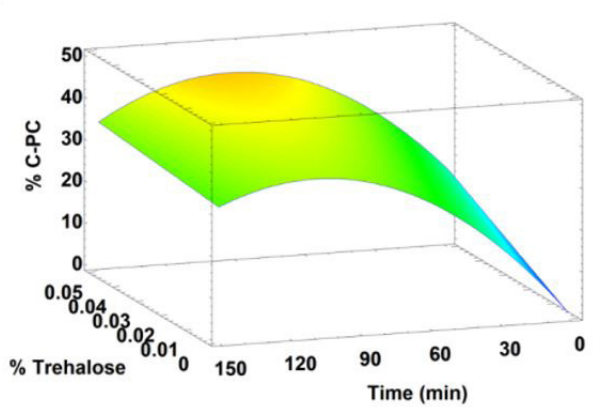


Table 2. Analysis of Variance for \% C-PC when using gastric juice without enzyme.

\begin{tabular}{|c|c|c|c|c|c|}
\hline Source & Sum of Squares & $\overline{D f}$ & Mean Square & F-Ratio & P-Value \\
\hline A:Size & 2.11108 & 1 & 2.11108 & 3.09 & 0.0832 \\
\hline B:Citric Acid & 5.55428 & 1 & 5.55428 & 8.13 & 0.0057 \\
\hline C:Trehalose & 93.3046 & 1 & 93.3046 & 136.58 & 0.0000 \\
\hline D:Time & 20.4522 & 1 & 20.4522 & 29.94 & 0.0000 \\
\hline $\mathrm{AB}$ & 34.6372 & 1 & 34.6372 & 50.70 & 0.0000 \\
\hline $\mathrm{AC}$ & 8.12711 & 1 & 8.12711 & 11.90 & 0.0010 \\
\hline $\mathrm{BC}$ & 100.05 & 1 & 100.05 & 146.46 & 0.0000 \\
\hline DD & 5.07489 & 1 & 5.07489 & 7.43 & 0.0081 \\
\hline $\mathrm{ABC}$ & 13.0767 & 1 & 13.0767 & 19.14 & 0.0000 \\
\hline CDD & 3.61858 & 1 & 3.61858 & 5.30 & 0.0244 \\
\hline Total error & 47.1369 & 69 & 0.683143 & & \\
\hline Total (corr.) & 485.153 & 79 & & & \\
\hline
\end{tabular}

Table 3. Analysis of Variance for \% TPC when using gastric juice with pepsin.

\begin{tabular}{lccccc}
\hline \multicolumn{1}{c}{ Source } & Sum of Squares & Df & Mean Square & F-Ratio & P-Value \\
\hline A:Citric acid & 88.3964 & 1 & 88.3964 & 52.14 & 0.0000 \\
B:Trehalose & 974.991 & 1 & 974.991 & 575.09 & 0.0000 \\
C:Time & 5.80242 & 1 & 5.80242 & 3.42 & 0.0728 \\
AB & 20.2221 & 1 & 20.2221 & & 0.0015 \\
Total error & 59.3377 & 35 & 1.69536 & \\
Total (corr.) & 1148.75 & 39 & & \\
\hline
\end{tabular}

of confidence. The maximum amount of C-PC recovered was around $38 \% \mathrm{~m} / \mathrm{m}$ of that added initially, Figure $1 \mathrm{~b}$. According to the ANOVA analysis, the most important factor is the interaction among citric acid and trehalose (BC) followed by trehalose itself (C). Again, the optimal result was achieved ca. $110-120$ minutes of digestion in the product presentation of $1 \mathrm{~g}$ added with trehalose and citric acid, Figure $1 b$.

\subsection{Effect of the studied factors in phycocyanin release from gelatin candies using gastric fluid with enzyme (pepsin)}

Given the previous results, we decided to prepare only gelatin candies of $1 \mathrm{~g}$ and studied all other factors in the simulated gastric juice added with pepsin. Since gelatin candies added with phycobiliproteins are mostly proteins, the presence of the gastric enzymes is an interesting factor to analyze when studying the stability of C-PC in the stomach.

The ANOVA for $\% \mathrm{~m} / \mathrm{m}$ of recovered TPC showed that all factors were statistically significant with $90 \%$ confidence, as well as the interaction among citric acid and trehalose, this last being quite the most important factor, Table 3.

The regression analysis produced the following Equation 6 explaining the effect of each factor over the response:

$$
\begin{aligned}
& \% m / m \text { TPC }=549.801 * \text { Trehalose }+1.053 * \text { Time - } \\
& 3.156 * \text { Trehalose }^{*} \text { Time }-0.00489 * \text { Time }^{2}
\end{aligned}
$$

In Equation 6 it is observed that recovery of TPC is highly dependent on the presence of trehalose, but also time is an important factor. This model has a $\mathrm{R}^{2}=97.1 \%$ and an estimated standard error $=9.83$, which is good enough and offers the possibility to be used for extrapolation purposes. According to the optimization procedure the maximum amount to be recovered under the studied conditions will be $68.46 \% \mathrm{~m} / \mathrm{m}$ when trehalose is at its maximum concentration of $0.05 \% \mathrm{~m} / \mathrm{m}$ at 90 minutes of digestion, however the zone of maximum extraction goes from 54 to 115 minutes when trehalose is at its highest concentration, Figure 1c. Equation 6 could predict a work zone for good results according to the needs of every case scenario.

In Table 4 it is shown the ANOVA for recovered C-PC under the same conditions described above. It could be observed the same pattern in the significant factors, with trehalose being the most important. According to the main effects analysis of the factors, the presence of inclusion of citric acid in the formulation has a significant negative effect in the result, however, the regression procedure showed that this component has no real impact in the percentage of $\mathrm{C}-\mathrm{PC}$ which can be recovered in digestive juice added with pepsin and it is shown in Equation 7.

$$
\begin{aligned}
& \% \mathrm{~m} / m C-P C=343.672 * \text { Trehalose }+0.665 * \text { Time }- \\
& 1.864 * \text { Trehalose }^{*} \text { Time }-0.003 * \text { Time }^{2}
\end{aligned}
$$

The optimization procedure for Equation 7 showed in Figure 1d. It is predicted a maximum release of $44 \% \mathrm{~m} / \mathrm{m}$ of the added $\mathrm{C}$-PC when trehalose is at $0.05 \% \mathrm{~m} / \mathrm{m}$ and time equals to 93.5 minutes. Different from the results in digestive juice without enzyme, the time reduction diminished by $30 \mathrm{~min}$, this could be attributed to the enzymatic activity over the proteinic content in 
Table 4. Analysis of Variance for \% C-PC when using gastric juice with pepsin.

\begin{tabular}{lccccc}
\hline \multicolumn{1}{c}{ Source } & Sum of Squares & Df & Mean Square & F-Ratio & P-Value \\
\hline A:Citric acid & 45.3576 & 1 & 45.3576 & 36.18 & 0.0000 \\
B:Trehalose & 447.376 & 1 & 447.376 & 356.86 & 17.03 \\
C:Time & 21.3463 & 1 & 21.3463 & 4.86 & 0.0000 \\
AB & 6.0879 & 1 & 6.0879 & & 0.0002 \\
Total error & 43.8771 & 35 & 1.25363 & \\
Total (corr.) & 564.045 & 39 & & \\
\hline
\end{tabular}

the gelatin candy. However, after 120 min the concentration of $\mathrm{C}-\mathrm{PC}$ is still higher than in the previous result without enzyme, achieving $41.9 \% \mathrm{~m} / \mathrm{m}$ C-PC released.

The previous results have shown that peptic enzyme (i.e. pepsin) in gastric juice is not prejudicial, but beneficial to release $\mathrm{C}-\mathrm{PC}$ from the gel-matrix. It is suggested according to our results that gelatin also acts as protectant of the phycocyanin, which in turn is not directly exposed to the acidic conditions of the stomach helping to preserve its integrity for longer periods of time. Among the parameters considered in gelatin formulations for pharmaceutical products are water quantity, temperature at which the active substance is added to the formulation as well as the acidity of the matrix (Delgado, 2015; Estrada, 2012). In this regard, the results concerning the product size suggest the best option for gelatin candies is to prepare them is small sizes, e.g. $1 \mathrm{~g}$. The most probable explanation to this phenomenon is that there is a major dehydration of the product given the surface area exposed to the environment, which in turn contributes to increase the effects of trehalose and citric acid in replacing water molecules in the vicinity of the phycobiliproteins.

Besides, as observed above the presence of the trehalose was the most significant factor among all-studied. Trehalose is a disaccharide of glucose with interesting properties for the food industry, its glucose-glucose bonds are not easily hydrolysed under acidic conditions, high temperatures or in the presence of glucosidases; also, trehalose acts as antioxidant creating crystal networks, all this leads to an increase in the stability of biomolecules in food (Feofilova et al., 2014; Köper \& Bellissent-Funel, 2002; Ohtake \& Wang, 2011). Its protective effect can be explained with one or more of the following theories: i) direct trehalose interaction with biomolecules promotes water replacement in the molecule's surface allowing it to preserve its former structure; ii) trehalose forms amorphous phases with crystals of high transition temperature; iii) this disaccharide delays the protein dynamic as a result of an increase in viscosity in the hydration layer affecting the movements' geometry of the protein (Köper \& Bellissent-Funel, 2002). It has been reported that glucose-glucose bonds in trehalose are not easily hydrolyzed in acidic medium, at high temperatures or with glucosidases (Feofilova et al., 2014), this could explain part of the protection conferred by trehalose to the phycobiliproteins. Moreover, trehalose has important characteristic that made it a desirable food additive, helps to preserve flavor, to reconstitute dehydrated foods, and limits the interaction of food ingredients with air avoiding their oxidation (Köper \& Bellissent-Funel, 2002; Ohtake \& Wang, 2011; Ribeiro \& Veloso, 2021). Therefore, the inclusion of this sugar as additive in gelatin candies is advised in this work.
We have tested also citric acid as preservative; this is one of the most used in candies because it is cheap, highly soluble and potentialize the product flavours (Ge et al., 2021) and as stated before, one of the most active additives inhibiting the PC degradation. Other authors have explored the inclusion of citric acid as well as some sugars such as glucose, sucrose or other molecules like sodium chloride, ascorbic acid, and sorbitol. But citric acid seemed to be the best one in preserving the pigment quality over extended periods of time (Kannaujiya et al., 2018; Kannaujiya \& Sinha, 2016; Wu et al., 2016). The importance of citric acid in these formulations can be explained by the report of Pan-utai et al. (2018) who describe the molecule of citric acid as kosmotropic, i.e. it helps to preserve the protein structure by altering the neighbor water molecules. Even when citric acid seems to have negative impact on the recovery of TPC or C-PC when pepsin is present in the synthetic gastric juice, we cannot discourage its addition in the formulation; as stated before, its function is important as $\mathrm{pH}$ regulator and gives acid flavor which is highly appreciated in gelatin, furthermore it is a natural occurring preservative (Gómez \& Sánchez, 2014).

In both results with pepsin in the gastric juice, we could observe a degradation of the phycocyanin after 110 - 120 minutes of digestion. It is important to notice that gastric emptying generally occurs after 120 minutes of receiving food which is rich in water and carbohydrates, the case of gelatin candies; then, this goes to the intestine (the target organ for nutrient's absorption) where the bile-salts interacts with food (Nagaoka et al., 2005), given this time we consider this kind of formulation can be used to deliver labile components to the digestive system. Another outcome presented in this work, it is that all the used ingredients are used in most confectionery industries, namely gelatin and citric acid and, most recently trehalose. Since the gelatin candies used in this study were prepared in a candy factory, we consider that the results presented here are suitable for other similar industrial processes.

Finally, in this report we have shown that phycocyanin is stable and, preserves its integrity when added to gummy candies given a workspace where the final user can decide the best combination to set all the operational and formulation parameters within it. In this work we have used the Response Surface Methodology, which is one of the tools used nowadays to produce these workspaces, also called design spaces. For most industrial processes the inclusion of design spaces is advised since it not strictly limiting to only one set of fixed parameters, but a range of operational parameters. In fact, it has been reported recently that the Food and Drug Administration recommends the establishing of experimental spaces to assure quality (Manzon et al., 2020). Then, we have shown an example 
using this approach which is suitable for risk-free decision making in food industry.

\section{Conclusions}

It was observed that gelatin candies can be a good vehicle to deliver phycocyanin $\mathrm{C}$ to the intestine when added with trehalose. It was demonstrated a time of maximum deliver of the pigment from 100 to 120 minutes, which is the average time to empty the stomach when digesting gelatin products. Even when we have shown that phycocyanin $\mathrm{C}$ can stand the digestive juices further research is needed. Despite of the protective effect of the gelling matrix and added trehalose in the candy, the released percentage could be still low for some commercial purposes. There is still lack of information on the interaction of trehalose and phycocyanin C. Besides, it would be desirable to evaluate the effect of the bile-salts in phycocyanin C stability to determine the amount of pigment with nutraceutical impact to be released in the intestines.

\section{Availability of data and material}

The datasets generated during and/or analyzed during the current study are available from the corresponding author on reasonable request.

\section{Acknowledgements}

The authors express their gratitude to the people of Centro de Investigación para el Desarrollo Industrial (CIDI) of the Universidad Autónoma de Guadalajara as well as to the factory Gomitas Selectas Domi de Jalisco for their support in the development of this project.

\section{References}

Ahuja, K., \& Mamtani, K. (2019). Phycocyanin Market Analysis 2019-2025 Growth Statistics Report. Retrieved from https://www.gminsights. com/industry-analysis/phycocyanin-market

Céspedes, N. C. V. (2019). Estudio comparativo de las propiedades fisicas de distintos hidrocoloides en un sistema de digestion in vitro (Thesis). Universidad de Chile, Santiago.

Delgado, A. Y. C. (2015). Efecto de las condiciones de secado por aspersión en la obtención de un colorante natural a partir de extractos líquidos de cúrcuma (Curcuma longa L) (Masters thesis). Retrieved from https:// repositorio.unal.edu.co/bitstream/handle/unal/53973/1086549677.2015. pdf? sequence $=1$ \&isAllowed $=y$.

Escalante, F. M., \& Pérez-Rico, D. A. (2021). Advancements in algae in nutraceutical and functional food. In G. Rajauria \& Y. V. Yuan (Eds.), Recent advances in micro and macroalgal processing: food and health perspectives (1st ed, pp. 506-536). New York: John Wiley and Sons. http://dx.doi.org/10.1002/9781119542650.ch18.

Estrada, A. C. P. (2012). Propuesta de una formulación de gomitas pediátricas con metamizol sódico (Thesis). Universidad Nacional Autónoma de México, Zaragoza.

Feofilova, E. P., Usov, A. I., Mysyakina, I. S., \& Kochkina, G. A. (2014). Trehalose: chemical structure, biological functions, and practical application. Microbiology, 83(3), 271 -283. http://dx.doi.org/10.1134/ S0026261714020064. PMid:25844437.
Ge, H., Wu, Y., Woshnak, L. L., \& Mitmesser, S. H. (2021). Effects of hydrocolloids, acids and nutrients on gelatin network in gummies. Food Hydrocolloids, 113, 106549. http://dx.doi.org/10.1016/j. foodhyd.2020.106549.

Gómez, M. M. R., \& Sánchez, N. E. O. (2014). Confitería de lo artesanal a la tecnología (2nd ed.). Aguascalientes: Universidad Autonoma de Aguascalientes.

Izquierdo, J., \& Feldman, P. (2019). 2019 Nutraceuticals market assessment. Reston: PMMI.

Jespersen, L., Strømdahl, L. D., Olsen, K., \& Skibsted, L. H. (2005). Heat and light stability of three natural blue colorants for use in confectionery and beverages. European Food Research and Technology, 220(3-4), 261-266. http://dx.doi.org/10.1007/s00217-004-1062-7.

Kannaujiya, V. K., \& Sinha, R. P. (2016). Thermokinetic stability of phycocyanin and phycoerythrin in food-grade preservatives. Journal of Applied Phycology, 28(2), 1063-1070. http://dx.doi.org/10.1007/ s10811-015-0638-X.

Kannaujiya, V. K., Kumar, D., Pathak, J., \& Sinha, R. P. (2018). Phycobiliproteins and their commercial significance. In A. K. Mishra, D. N. Tiwari, \& A. N. Rai (Eds.), Cyanobacteria: from basic science to applications (pp. 207-216). Amsterdam: Elsevier Academic Press. https://doi.org/10.1016/B978-0-12-814667-5.00010-6

Kefayat, A., Ghahremani, F., Safavi, A., Hajiaghababa, A., \& Moshtaghian, J. (2019). C-phycocyanin: a natural product with radiosensitizing property for enhancement of colon cancer radiation therapy efficacy through inhibition of COX-2 expression. Scientific Reports, 9(1), 19161. http://dx.doi.org/10.1038/s41598-019-55605-w. PMid:31844085.

Khan, M. I., Shin, J. H., \& Kim, J. D. (2018). The promising future of microalgae: current status, challenges, and optimization of a sustainable and renewable industry for biofuels, feed, and other products. Microbial Cell Factories, 17(1), 36. http://dx.doi.org/10.1186/ s12934-018-0879-x. PMid:29506528.

Köper, I., \& Bellissent-Funel, M. C. (2002). Hindered protein dynamics in the presence of a cryoprotecting agent. Applied Physics. A, Materials Science \& Processing, 74(Suppl. II). http://dx.doi.org/10.1007/ s003390201880.

Liu, Y., Feng, Y., \& Lun, J. (2012). Aqueous two-phase countercurrent distribution for the separation of c-phycocyanin and allophycocyanin from Spirulina platensis. Food and Bioproducts Processing, 90(2), 111-117. http://dx.doi.org/10.1016/j.fbp.2011.08.002.

Madrigal, P. R., Moreno, A. I., \& Robles, I. G. C. (2020). Tecnología de elaboración de gomitas de grenetina adicionadas con vitamina C. Humanidades, Tecnología y Ciencia Del Instituto Politécnico Nacional, 22, 1-6.

Manzon, D., Claeys-Bruno, M., Declomesnil, S., Carité, C., \& Sergent, M. (2020). Quality by design: comparison of design space construction methods in the case of design of experiments. Chemometrics and Intelligent Laboratory Systems, 200, 104002. http://dx.doi.org/10.1016/j. chemolab.2020.104002.

Mexico. Comisión Permanente de la Farmacopea de los Estados Unidos Mexicanos. (2018). Farmacopea de los Estados Unidos Mexicanos (12th ed., pp. 343-350). México: Secretaría de Salud.

Milledge, J. J. (2011). Commercial application of microalgae other than as biofuels: a brief review. Reviews in Environmental Science and Biotechnology, 10(1), 31-41. http://dx.doi.org/10.1007/s11157010-9214-7.

Nagaoka, S., Shimizu, K., Kaneko, H., Shibayama, F., Morikawa, K., Kanamaru, Y., Otsuka, A., Hirahashi, T., \& Kato, T. (2005). A novel protein C-phycocyanin plays a crucial role in the hypocholesterolemic action of Spirulina platensis concentrate in rats. The Journal of Nutrition, 
135(10), 2425-2430. http://dx.doi.org/10.1093/jn/135.10.2425. PMid:16177207.

Neter, J., Kutner, M., Nachtsheim, C., \& Wasserman, W. (1996). Applied linear statistical models. New York: McGraw-Hill.

Odjadjare, E. C., Mutanda, T., \& Olaniran, A. O. (2017). Potential biotechnological application of microalgae: a critical review. Critical Reviews in Biotechnology, 37(1), 37-52. http://dx.doi.org/10.3109/0 7388551.2015.1108956. PMid:26594785.

Ohtake, S., \& Wang, Y. J. (2011). Trehalose: current use and future applications. Journal of Pharmaceutical Sciences, 100(6), 2020-2053. http://dx.doi.org/10.1002/jps.22458. PMid:21337544.

Pan-utai, W., Kahapana, W., \& Iamtham, S. (2018). Extraction of C-phycocyanin from Arthrospira (Spirulina) and its thermal stability with citric acid. Journal of Applied Phycology, 30(1), 231-242. http:// dx.doi.org/10.1007/s10811-017-1155-x.

Pérez-Rico, D. A., Alarcón-Jiménez, J. L., González-Morales, E., Guerra-álvarez, L. F., Ramírez-Vázquez, J. C., Gutiérrez-Pulido, H., \& Escalante, F. M. E. (2020). Phycocyanin thermo-photostability: An accelerated life-test analysis. Journal of the Mexican Chemical Society, 64(3), 218-229. http://dx.doi.org/10.29356/jmcs.v64i3.1157.

Ribeiro, J. S., \& Veloso, C. M. (2021). Microencapsulation of natural dyes with biopolymers for application in food: A review. Food Hydrocolloids, 112, 106374. http://dx.doi.org/10.1016/j.foodhyd.2020.106374.

Wu, H. L., Wang, G. H., Xiang, W. Z., Li, T., \& He, H. (2016). Stability and antioxidant activity of food-grade phycocyanin isolated from Spirulina platensis. International Journal of Food Properties, 19(10), 2349-2362. http://dx.doi.org/10.1080/10942 912.2015 .1038564 . 